\title{
Management of 28 Weeks of Gestation with Traumatic Splenic Rupture
}

\author{
Sheela $\mathrm{SR}^{1}$, Shashirekha $\mathrm{CA}^{2}$, Ashritha $\mathrm{R}^{1}$, Sreeramulu $\mathrm{PN}^{2}$ \\ Departments of ${ }^{1}$ Obstetrics and Gynecology and ${ }^{2}$ Surgery, Sri Devaraj URS Medical College and Research Centre, Kolar, Karnataka, \\ India.
}

\section{Corresponding Author: \\ Dr. Ashritha R}

Email: ashritharhms@gmail.com

This is an Open Access article distributed under the terms of the Creative Commons Attribution License (creativecommons.org/ licenses/by/3.0).

Received Accepted Published
October 26, 2016

December 29, 2016

January 25, 2017

\begin{abstract}
Background: Failure to recognize splenic rupture in pregnant woman can prove fatal for both mother and fetus. Case Report: A 22 year old gravida-2 was admitted at 28 weeks of gestation with abdominal pain following road side accident. Ultrasound abdomen highlighted splenic laceration/contusion. She underwent splenectomy and subsequently had a spontaneous labor at 39 weeks. Conclusion: Splenic rupture during pregnancy can cause diagnostic dilemma since pregnancy related complications may mask its symptoms.
\end{abstract}

Keywords: Abdominal Pain, Accidents, Pregnancy, Splenectomy, Splenic Rupture.

\section{Introduction}

The estimate of trauma among pregnant women in developed countries is around 6-7\% and is commonest non-obstetric cause of fetal death [1]. A successful maternal and fetal outcome is dependent on high index of suspicion, immediate surgical intervention, multidisciplinary approach and good postoperative care. We hereby report successful maternal and fetal outcome in pregnant woman with splenic rupture following road accident.

\section{Case Report}

A 22 year old woman, second gravida with 7 months of amenorrhea presented to our casualty with alleged history of road traffic accident (RTA). The motorcycle on which she was travelling was hit by a high speeding vehicle. She had a fall and sustained multiple injuries. Patient sustained trauma to the abdomen, chin and back. She had complaints of severe agonizing pain abdomen on left side (score of 10 out of 10 on visual analog score), which was non-radiating and aggravated on changing position. The physical examination showed conscious, oriented (GCS 15/15), anemic patient having tachycardia (116 beats per minute), hypotension $(90 / 60 \mathrm{~mm} \mathrm{Hg})$ with contusion over chin and left gluteal region. Her abdominal examination revealed lower abdominal distension, uterine size of 28 weeks, free fluid and regular fetal heart rate of 158 beats per minute. Ultrasound showed large ill-defined echotexture in spleen most likely laceration/contusion, mild-moderate hemoperitoneum, single live intrauterine gestation appropriate to 29 weeks with cephalic presentation, biophysical profile of $8 / 8$. Laboratory data revealed hemoglobin $7.4 \mathrm{~g} \%$, platelets: $88000 / \mathrm{mm}^{3}$, INR: 3.01, total protein: $4.9 \mathrm{~g} / \mathrm{dL}$, albumin: $2.3 \mathrm{~g} / \mathrm{dL}$.

Patient underwent emergency exploratory laparotomy with splenectomy. Intraoperative findings revealed hemo-peritoneum around 700$800 \mathrm{ml}$, grade $\mathrm{V}$ splenic injury extending up to the hilum. Patient was shifted to intensive care unit for 3 days. Patient was transfused with total 6 pints of packed cell transfusion, 8 pints of fresh frozen plasma, 4 pints of platelets during complete hospital stay preoperatively and postoperatively. Patient was stable with healthy wounds and discharged on $13^{\text {th }}$ day after pneumococcal, meningococcal, 
Haemophilus influenze and influenza vaccination. The patient was on regular follow-up and admitted at 39 weeks of gestation for safe confinement and close monitoring. She went into spontaneous labor at 39 weeks 5 days gestation, had an uncomplicated normal delivery of healthy term female baby of weight $3.2 \mathrm{kgs}$. Mother and baby were healthy at discharge.

\section{Discussion}

Splenic injury during pregnancy after blunt abdominal trauma is extremely rare. The clinical, biological and radiological signs are modified by the physiological and anatomical changes during pregnancy. In pregnancy, the occurrence of recurrent bleeding, the chance of concomitant uterine injuries and the risk of fetal loss should modify the surgeon's approach to splenic rupture after abdominal blunt trauma. The diagnosis of splenic rupture is frequently difficult, as the presence of the pregnancy leads the obstetrician to concentrate on the possibility of uterine or adnexal injury [2].

The clinical signs and symptoms normally associated with intraperitoneal bleeding may be poorly defined. As in this case, the presenting compliant was abdominal pain with little to indicate its site and character. The presence of hemoperitoneum and peritoneal irritation may be difficult to detect on uterine palpation and auscultation of fetal heart sounds becomes hesitant. Albuminuria may be present and add further to the difficulty of distinguishing between intraperitoneal bleeding due to splenic rupture and that due to abruptio placentae. The basis of adequate therapy is the correct diagnosis at an early stage followed by adequate blood replacement and early surgical intervention to arrest bleeding. Caesarean section had to be performed in some cases where a term sized uterus prevented adequate exposure of the splenic fossa [3]. The spleen plays a crucial role in the body's ability to fight against bacteria. Living without the organ is more prone to develop infections, especially precarious ones such as Streptococcus pneumoniae, Neisseria meningitidis, and Haemophilus influenzae. These bacteria can also cause severe pneumonia, meningitis, and other serious infections. There are chances of immune thrombocytopenic purpura, which is a serious complication to be kept in mind [4]. Vaccinations to cover these bacteria should ideally be given to patients, two weeks before planned surgery or roughly two weeks after emergency surgery.

\section{Conclusion}

This case illustrates the need to consider splenic rupture as one of the differential diagnosis in pregnant women after trauma. Immediate surgical intervention is needed to ensure the survival of both mother and fetus, patient should be monitored carefully with regular follow up and proper institutional delivery.

Contributors: SSR: Obstetric management; SCA: Surgical management; AR: Obstetric management, manuscript writing; SPN: Manuscript editing. AR will act as guarantor. All authors approved the final version of manuscript.

Funding: None; Competing interests: None stated.

\section{References}

1. El-Kady D, Gilbert WM, Anderson J, Danielsen B, Towner D, Smith LH. Trauma during pregnancy: an analysis of maternal and fetal outcomes in a large population. Am J Obstet Gynecol. 2004;190:1661-1668.

2. Dave A, Dhand H, Mujalde A. Spontaneous rupture of spleen during pregnancy. J Obstet Gynecol India. 2012;62:692-693.

3. Dahiya K, Sirohiwal ND, Dahiya A. Traumatic splenic rupture in pregnancy. Journal of Gynecologic Surgery. 2009;25:33-36.

4. Mehmet H, Muge H, Nese G. Postpartum spontaneous splenic rupture: a case report. J Turk Ger Gynaecol Assoc. 2004;5:153-155. 